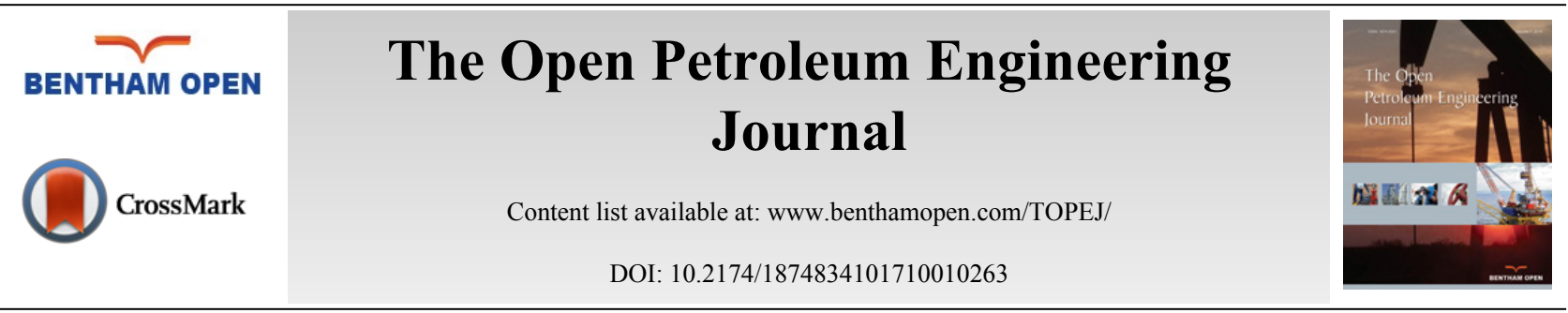

RESEARCH ARTICLE

\title{
Experimental Investigation of Polyvinylpyrrolidone for Application as a Demulsifier for Water-in-Oil Emulsion
}

\author{
Mysara Eissa Mohyaldinn, Logeswuran Rammudo and Muhammad Ayoub* \\ Petroleum Engineering Department, Universiti Teknologi Petronas, Bandar Seri Iskandar, Perak, Malaysia
}

Received: June 06, 2017

Revised: October 08, 2017

Accepted: November 15, 2017

\begin{abstract}
:
Introduction:

Emulsification of produced immiscible mixed liquid of oil and water is a problem frequently recognized in surface production facilities in oil fields. The formed emulsions are required to be demulsified to avoid the negative consequences on piping and processing equipment. Nowadays, chemical demulsification is a preferable method to avoid or retard emulsification during the process of oil treatment.
\end{abstract}

\section{Materials and Methods:}

In the present study, Polyvinylpyrrolidone, poly-[1-(2-oxo-1-pyrrolidinyl)-ethylene] has been experimentally investigated as a chemical demulsifier for water-in-oil emulsion formulated by mixing a crude oil with synthesized oilfield produced water. Oilfield brines were synthesized by dissolving $\mathrm{NaCl}$ in deionized water to obtain salinity similar to the oilfield produced water. The sample of water-oil emulsion was prepared by agitation process at the condition of controlled rpm speed, ambient temperature and concentration of emulsifying agent. Stability of the emulsion was investigated using Turbiscan MA 2000 instrument.

\section{Results:}

The efficiency of the demulsification was screened using Bottle Test. It has been found that Polyvinylpyrrolidone, poly-[1-(2-oxo-1pyrrolidinyl)-ethylene] accelerates the separation of the emulsion as compared to blank ones (with no addition of PVP). A maximum demulsification performance of the PVP was observed at an optimum concentration of $60 \mathrm{ppm}$.

Keywords: Chemical demulsification, Demulsifier, Emulsion, Oil fields, PVP, Water-oil mixture.

\section{INTRODUCTION}

Oil production and processing are always accompanied with undesired formation of emulsion. An emulsion is formed as a result of dispersion of an immiscible liquid into another immiscible liquid [1 - 4]. There are numerous factors governing the formation of emulsion. During petroleum production, the emulsion formation takes place mainly due to the exposure of the produced fluids to continuous turbulence and agitation at different location along the flow stream. This agitation may occur at subsurface components or at surface components such as process facilities, transportation piping and refining facilities. In the recent decade, the presence of crude oil emulsion has been a significant challenge that the oil and gas industry is facing right now [5] due to the depletion of many mature oil reservoirs, and hence, increasing water production. The effect of this problem extends beyond the upstream operations and becomes a major problem during oil transportation and refining [6, 7]. In general, emulsion is expected whenever oil and water are concurrently pumped through the same pipeline [6]. Stable emulsion, however, will not form unless an emulsifying agent is present in the mixture $[6,7]$. The emulsifying agents are some organic or inorganic substances

\footnotetext{
* Address correspondence to this author at the Petroleum Engineering Department, Universiti Teknologi Petronas, Bandar Seri Iskandar, Perak, 32610, Malaysia; Tel: 0060-104260280; E-mail: mysara.eissa@utp.edu.my
} 
that contaminate the crude oil such as asphaltenes, resins and naphthenic acid. Resins are normally red coloured while asphaltenes are black or grey coloured. Both resins and aspheltenes compounds are made up of relatively highmolecular-weight, polar, polycyclic, aromatic ring compounds [7]. The asphaltene component is the most polar and a primary factor for stabilizing water in emulsion [8]. Both asphaltenes and resins are interfacial active materials that can adsorb on the surface of water droplets to stabilize water droplets in oil. This mainly happens due to the formation of a firm film at the water droplet. The rigid film like structure will safeguard the droplet from rupturing [9, 10].

Depending on which phase is continuous (primary) and which one is dispersed (secondary), emulsions are classified into water in oil $(\mathrm{W} / \mathrm{O})$, oil in water $(\mathrm{O} / \mathrm{W})$, or water in oil in water multiple emulsion $(\mathrm{W} / \mathrm{O} / \mathrm{W})$. The majority of the emulsions encountered in petroleum production belong to water-in-oil type. In the $(\mathrm{W} / \mathrm{O})$ emulsion, water is dispersed in the form of droplets in the continuous oil phase. The presence of active polar molecules in addition to natural, creates a strong attraction force between the water droplets with the oil phase resulting in stabilizing the water in oil emulsion [11]. Water in oil mixtures can be grouped into four states which are stable, mesostable, unstable and entrained water. Only stable and mesostable can be classified as emulsions [12].

During petroleum treatments, proactive measures have to be taken to treat emulsions. Following gravity-assisted separation, mechanical and chemical demulsification methods are normally adopted to break an emulsion and make it ready for water removal. Mechanical demulsification is normally done by utilizing equipment like water treater and coalescer. In some instances, transformer electrodes for electrostatic treatment are used. Chemical demulsification is performed using special chemicals that are able to display or weaken the emulsifying materials at the oil/water interface. One of the chemical demulsifying materials investigated in the current work is Polyvinylpyrrolidone, (PVP). The homopolymers of VP (Polyvinylpyrrolidone, PVP) is a chemical substance that is commonly used as an emulsifying agent to stabilize emulsion mixtures for special purpose. In petroleum industry, however, PVP has been argued to have a reverse effect on emulsion that it can act as demulsifier for water in oil emulsion. The demulsification performance of PVP has been investigated by Hanapi Mat and his co-workers, who have examined the demulsification efficiency of PVP (with a concentration of $10 \mathrm{ppm}$ ) on an emulsion formulated from water mixed with selected Malaysian oil samples at $70{ }^{\circ} \mathrm{C}$. Their experimental results showed increased oil separation from the water/oil emulsion with time [13]. Another evidence of exhibition of PVP as demulsifier was reported by Razi and others as a result of experimental investigation of many oil soluble chemicals including PVP [14]. The investigations have been conducted on an emulsion formed by mixing of $20 \%$ water with medium either $\left(868 \mathrm{~kg} / \mathrm{m}^{3}\right)$ or heavy $\left(1006 \mathrm{~kg} / \mathrm{m}^{3}\right) \mathrm{crude}$ oil at 800 $\mathrm{rpm}$ for $15 \mathrm{~min}$. Their results, however, indicated that the demulsification efficiency is somewhat lower compared to the other investigated demulsifiers.

\section{EXPERIMENTAL WORK}

The chemical material used for the preparation of synthetic formation water is sodium chloride $(\mathrm{NaCl})$. Oilfield brine was synthesized by dissolving $\mathrm{NaCl}$ in deionized water in order to obtain 30000 ppm salinity, which is similar to the oilfield associated water (Hing, 1999). The brine water as shown in Fig. (1) has been synthesized by dissolving $30 \mathrm{~g}$ of salt in $1000 \mathrm{ml}$ of the solution. The crude oil used for this study is Castila crude produced offshore and located at 250 $\mathrm{km}$ southeast of Bogota. This crude oil is classified as heavy crude with low sulfur content blend. The crude is believed to form a stable emulsion due to its interfacial active components. After the brine water was synthesized and the emulsion was formed, Polyvinylpyrrolidone (PVP) supplied from Sigma Aldrich has been tested as a demulsifier.

\subsection{Formation of Emulsion}

Water in oil emulsion has been prepared by agitation of crude oil at 600rpm using a standard three bladed propellers (Fig. 2). The emulsion formulation, instead of using a real emulsion, was followed in this work because the formulation allows controlling emulsion properties, and hence, make it easier to analyse the effect of different parameters. In addition, it is difficult to keep the real emulsion until conducting the experiments, as it will be affected by the history which will change the original properties of the emulsion. The emulsion preparation has been conducted under ambient temperature. Water was added to the oil gradually while the mixture was contiuously agitated to emulsify it. Verification to ensure that the emulsion prepared was water in oil was performed using bottle test as well as Turbiscan MA 2000. 


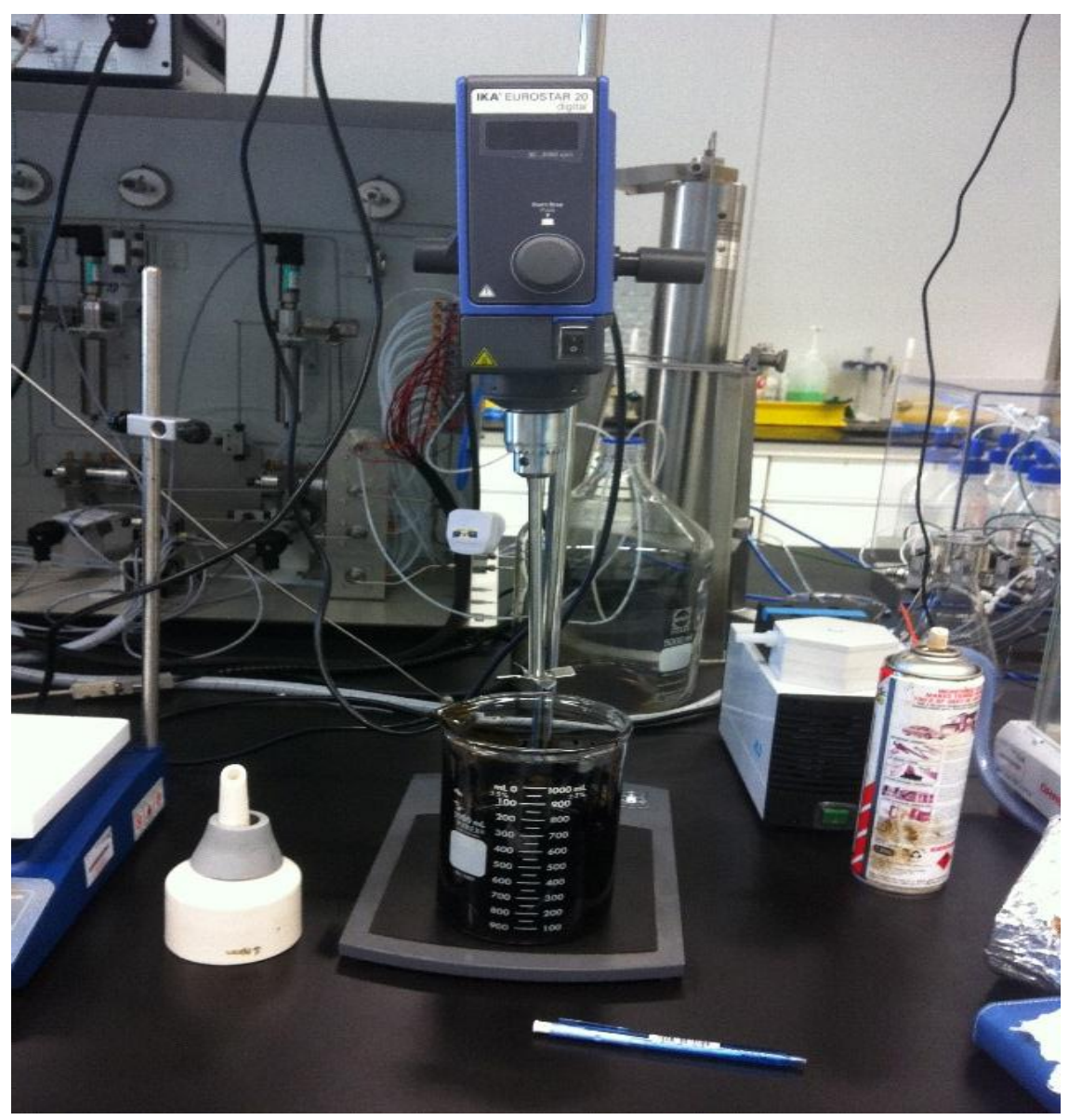

Fig. (1). Blade propeller used to stir the emulsion.
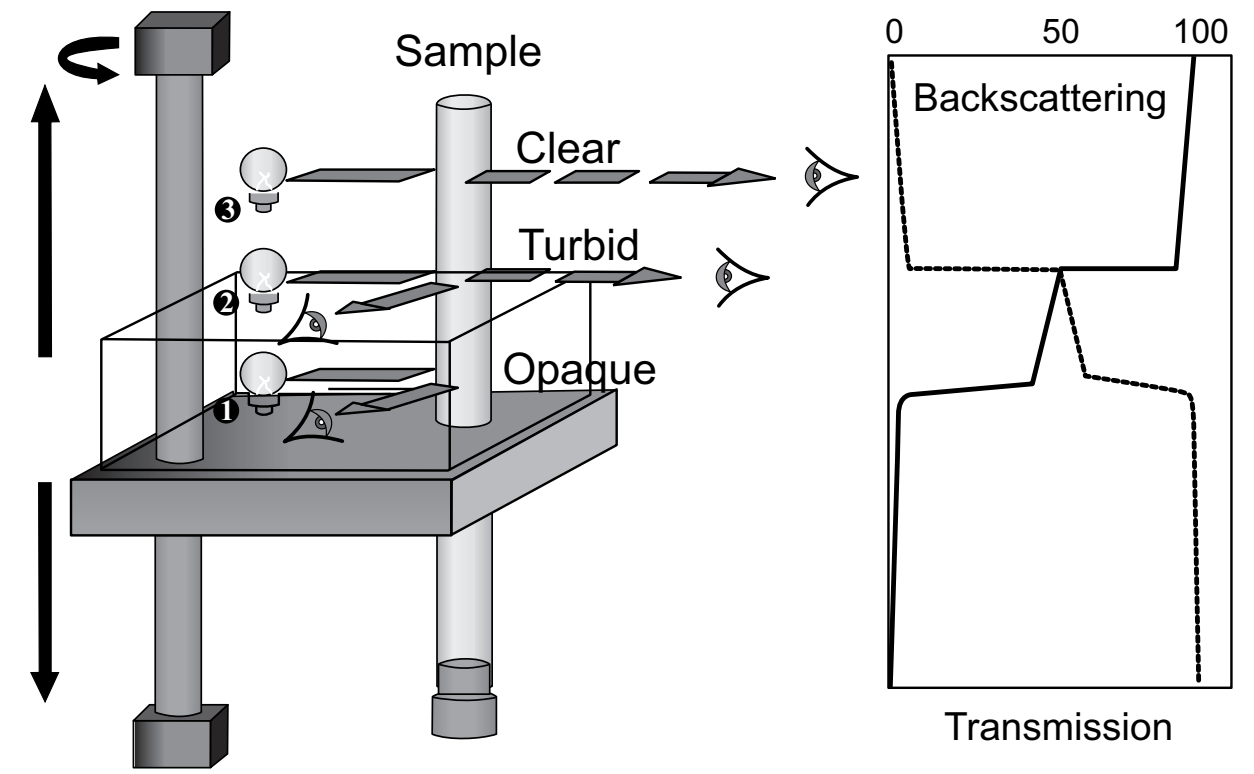

Fig. (2). Turbiscan MA2000 [4].

\subsection{Testing the Stability of an Emulsion (Turbiscan MA 2000)}

Stability studies of the emulsion have been conducted using Turbiscan MA 2000. Turbiscan MA 2000 is an automated, vertical scan macroscopic analyser that uses a near infrared light source combined with a double detection system involved in transmission and light scattering. The working mechanism of Turbiscan MA 2000 is shown in Fig. 
(2). Kinetic mode of this equipment showed the evolution of a sample by comparing transmission and backscattering graphs. There was an option to program the period of time to run the whole set up. This can enable the destabilization of kinetics to be determined over varying period of times.

The samples of water in oil stabilized emulsion were introduced in a cylindrical glass cell and inserted into the Turbiscan MA 2000. During each run of the experiments, the optical reading head of the Turbiscan MA 2000 scanned the whole length of the sample and acquired both the transmission and backscattered data every $40 \mu \mathrm{m}$ and every 60 min for $24 \mathrm{~h}$. The analysis of emulsion stability has been carried out by observing the variation of transmission profiles only over time. The stability or instability of the emulsion was observed and evaluated by conducting repeated multiple scans.

\subsection{Preparation of Demulsifier with Different Concentration}

The demulsifier was prepared with the desired concentration using the following equation.

$$
\frac{\text { Mass of solute }(g)}{\text { Mass of solution }(g)} \times 10^{6}
$$

To ensure the accuracy, a series of centrifuge bottles was used. Demulsifiers solution with concentrations of 10,20 , $50,55,60,65,70$, and $80 \mathrm{ppm}$ has been created using equation 2 . Polyvinylpyrolidone(PVP) weight to prepare the desired demulsifier concentration was determined using the electronic weighing balance. The measured demulsifiers were then diluted with ethanol solvent and added to the water in oil emulsion prepared previously. The system was stirred vigorously for 1 minute to mix the demulsifier and emulsion system.

\subsection{Demulsification Tests Using Bottle Test}

The emulsions were created from a synthesized brine and Castila crude. Fig. (3) shows the synthesized brine and Castila crude kept in a beaker prior to heating procedure (Fig. 3). After heating at $60^{\circ} \mathrm{C}$, the selected emulsion was stirred with homogenizer before it was poured in the bottle (Fig. 4) for carrying out the bottle test. The emulsion was left for 24 hours to record the percentage of water separation. This procedure was firstly applied for the emulsion without the addition of demulsifiers and for the demulsified emulsion with different concentrations.

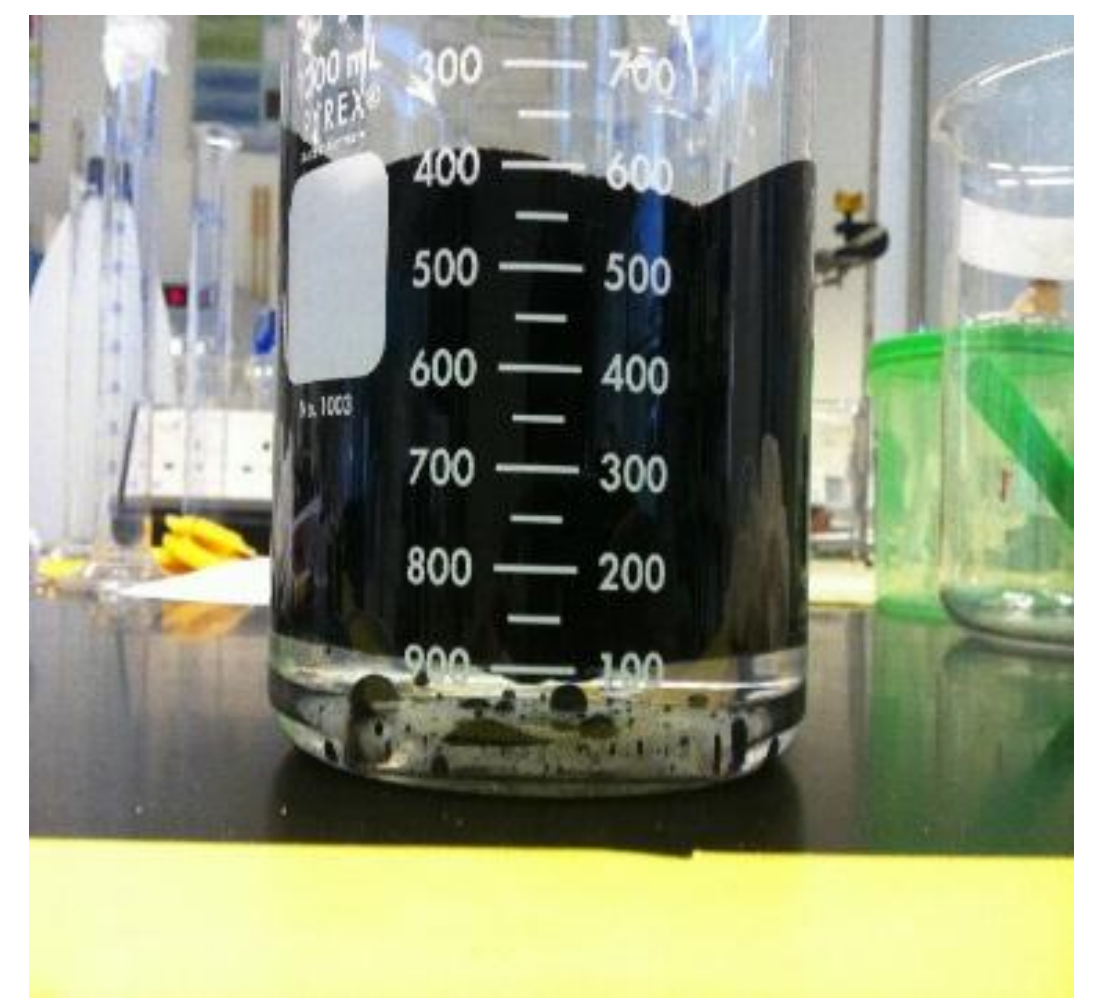

Fig. (3). Brine water and crude oil before heating and stirring procedure. 


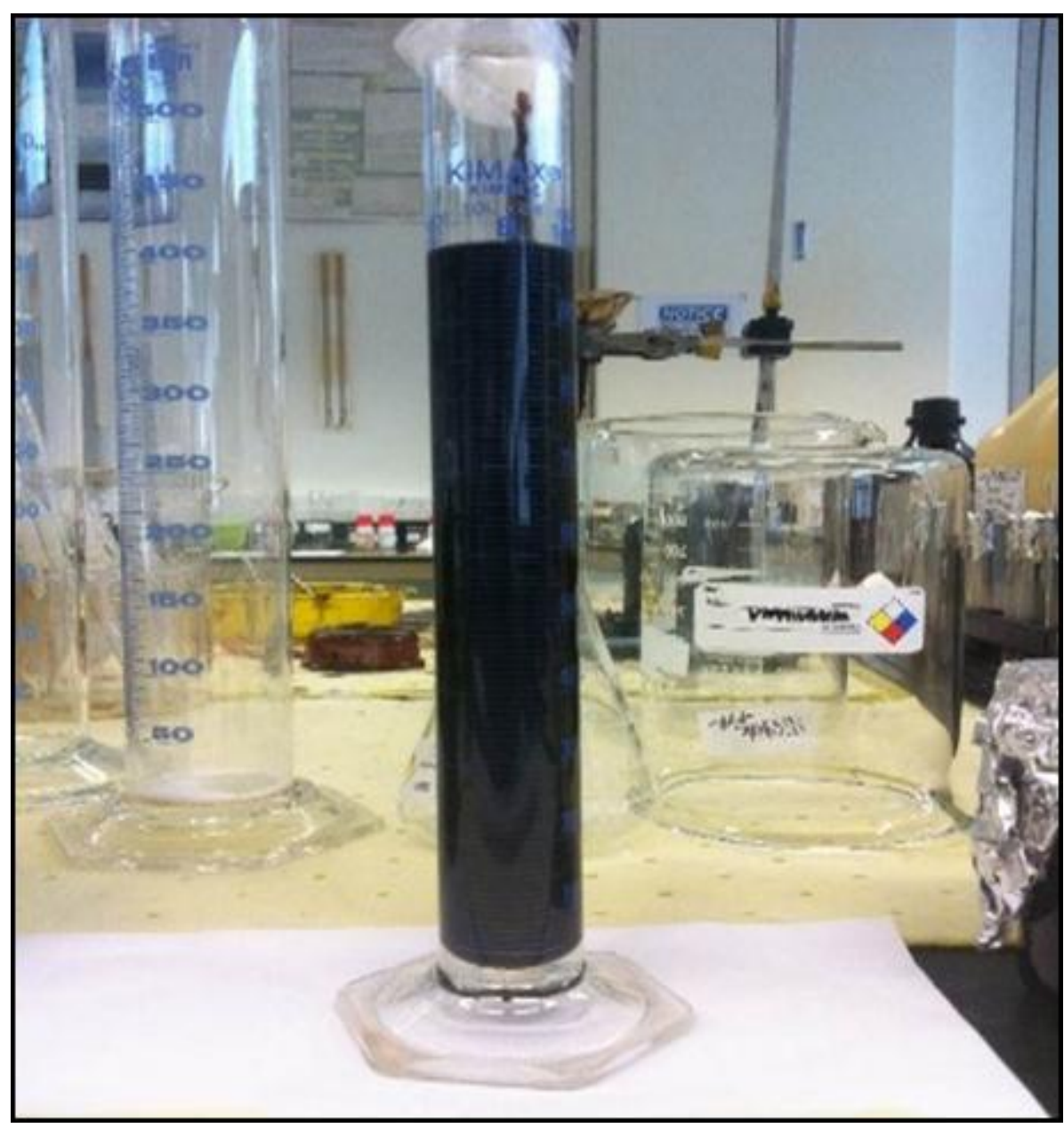

Fig. (4). Water in oil Emulsion after heating and stirring procedure.

\section{RESULTS AND DISCUSSION}

\subsection{Characterization of Crude Oil}

Density and viscosity were measured for Castila crude oil at ambient temperature. The density of the crude oil was measured using density meter DMA $35 \mathrm{~N}$. The viscosity of the crude oil was measured using a falling ball viscosity meter. The obtained measurement results are listed in Table $\mathbf{1 .}$

Table 1. Characteristics of castile crude oil.

\begin{tabular}{|c|c|}
\hline \multicolumn{2}{|c|}{ Castila Crude Oil (at 27 degrees Celsius) } \\
\hline Density & $941 \mathrm{kgm} 3$ \\
\hline Viscosity & $10200 \mathrm{cP}$ \\
\hline API Gravity & 18.71 \\
\hline
\end{tabular}

The density and viscosity of a crude oil are an important element for the characterization of the crude oil. Obtaining accurate viscosity and density values can be difficult, especially for live oil. Oil viscosity may affect the emulsions stability by two mechanisms that counter each other. On one hand, viscosity may reduce the emulsion stability due to hindrance or deceleration of the movement of emulsified materials from crude oil into the water interface. As a result, the interfacial tension between water and oil became lower and water droplets came closer to each other to form coalescence. Higher viscosity, however, may decelerate the movement of water droplets, which will result in higher stability of the emulsion (the emulsion becomes less likely to separate). The crude characterization results shown in Table 1 indicate that the crude oil falls within the range of heavy crude oils. In general, viscous heavy crude oil tends to create more stable emulsion due to the presence of active polar molecules. 


\subsection{Stability of Water in Oil Emulsion Using Bottle Test}

Water in oil emulsion was formed using 20: 80 water to oil ratio. Sample of brine water with 30000 ppm was used for the preparation of emulsion. At the test run of every bottle, the water separation in percent was obtained from the volume of water observed in the measuring cylinder. Equation 2 was used to calculate the separation efficiency in percentage.

$$
W s \%=\frac{V_{w s}}{V_{o}} \times 100 \%
$$

Where Ws is the percentage of water separated, Vms is the volume of water separated, and Vo is the original water volume.

Fig. (5) shows the variation in the separated water percentage with time for the plain emulsion ( 0 ppm demulsifier). The results showed that water started to separate after 1020 min (17 hours) and the maximum percentage of water separated was $9 \%$ after 1440 minutes ( 24 hours). This indicates that the emulsion was very stable. The blain emulsion test was conducted to set as the base case for comparison with the performance of demulsifier for the same emulsion.

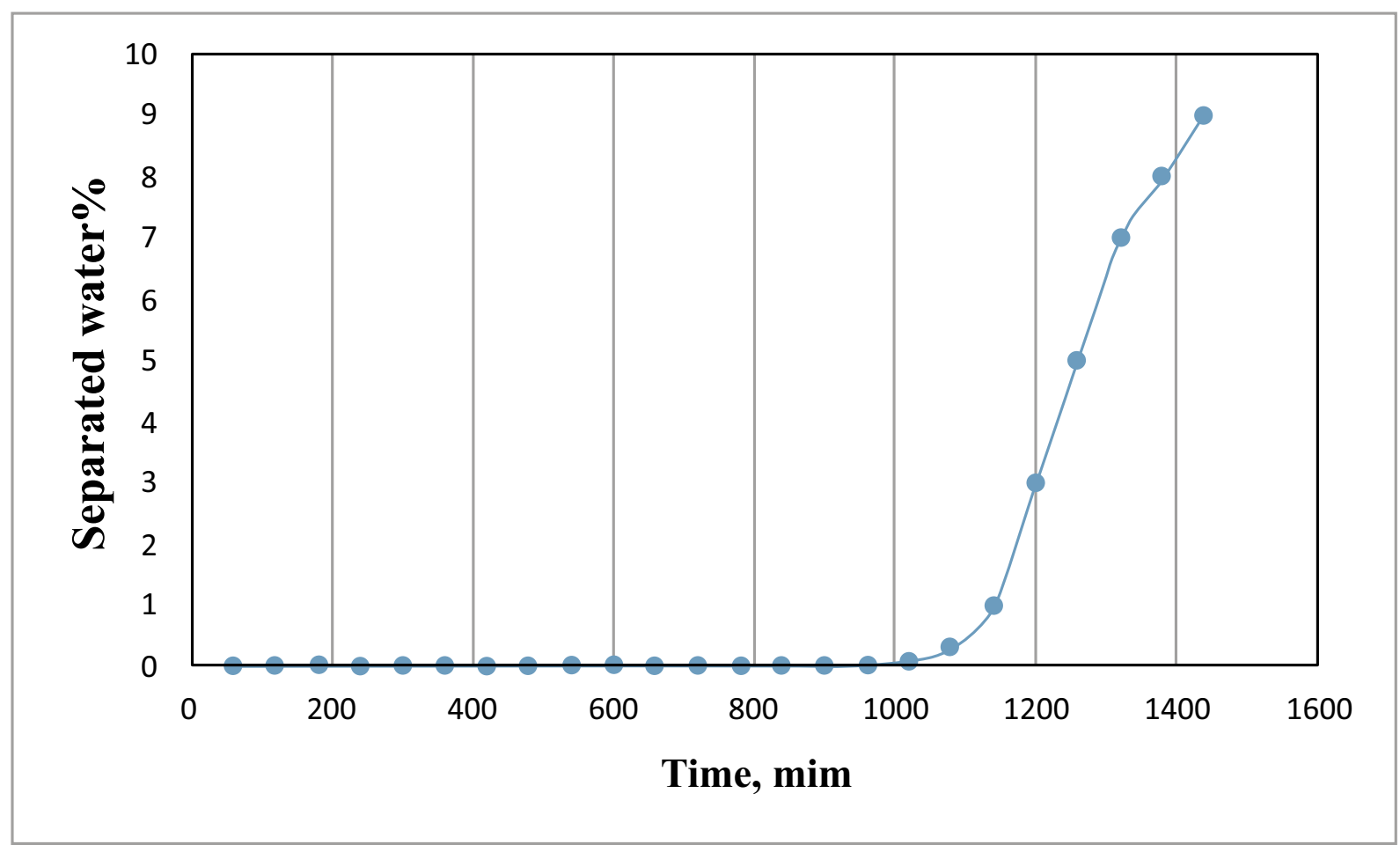

Fig. (5). Variation of separated water with time using bottle test.

\subsection{Analysis on the Water in Oil Emulsion Stability Using Turbiscan MA 2000}

The transmission profile as function of the tube length for 20: 80 (water: oil) stabilized emulsion was analyzed for emulsion stability. Fig. (6) indicates that the transmission increased at the bottom of the bottle due to the increase of the concentration of the dispersed phase (water). Cerimedo [15] stated that the transmission is directly dependent on the mean diameter of the droplets and oil volumetric fraction. The back scattering profiles at all times showed a peak at the bottom of the tube between $0-20 \mathrm{~mm}$ zone when displayed in the reference mode.

The peak is associated with the destabilization phenomenon called creaming and there was also a noticeable decrease in the transmission along the whole length of the tube which is the indication of flocculation or coalescence. This result is an evidence that the emulsion of $20 \%$ water cut with $80 \%$ of oil cut is fairly stable. Based on the transmission data from Turbiscan result, the small amount of sedimentation was formed. 


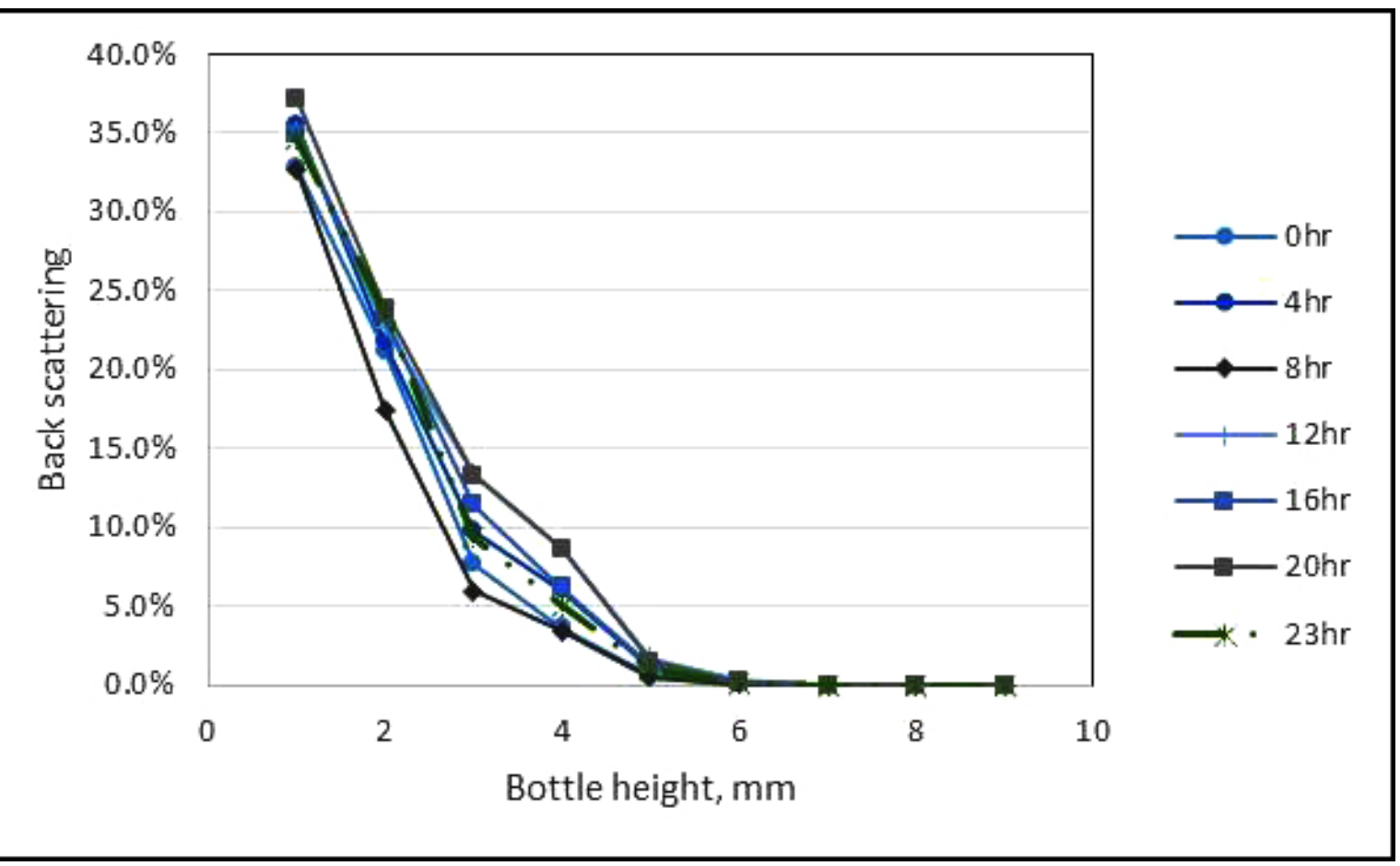

Fig. (6). Result from Turbiscan MA 2000 for water in oil emulsion stability.

\subsection{Effect of Mixing Rate Towards the Stability of Water in Oil Emulsion}

The relationship between the stability of water in oil emulsion due to the mixing rate was further analysed at mixing rate values of $300 \mathrm{rpm}, 400 \mathrm{rpm}, 500 \mathrm{rpm}$, and $600 \mathrm{rpm}$. The emulsion stability was calculated using Equation 3.

$$
\text { Emulsion Stability }=\left(1-\frac{\text { Volume of separated water }, m L}{\text { Original volume of water in emulsion }, m L}\right) \times 100
$$

The result shown in Fig. (7) represents the influence of shear rate on emulsion stability at crude oil volume fraction values of $60 \%, 70 \%$, and $80 \%$. It is shown in the plot that increasing the mixing shear rate resulted in the increase of stability of the emulsion, which is in agreement with the previous researchers' work. For instance, Ashrafizadeh and Kamran [16] pointed out that the emulsion stability significantly increased by increasing the mixing speed. The researchers have been conducting experiments on two types of oils, one is West Paydar and the other is diesel-bitumen, both are blended in water to form emulsions. The considered values of speed are 1000, 3000, 6000, 10,000 and 15,000 $\mathrm{rpm}$. The experiments have been conducted at temperature of $25^{\circ} \mathrm{C}$, with $\mathrm{pH}$ of 7 , mixing duration of $20 \mathrm{~min}$, surfactant concentration of $2 \mathrm{wt} . \%$, and oil content of $60 \mathrm{vol} . \%$. Based on their experimental results, the authors explicitly declared that the increase in the mixing speed "has a slight increasing effect on the viscosity of the emulsions while also increases the stability of the emulsions up to a desirable level". Fig. (8) shows the variation in water separation and emulsion stability of the two emulsion types with mixing speed as extracted from their original results. The emulsion stability in this figure was calculated using equation 3, assuming original volume of water to be $100 \mathrm{ml}$. It can be noted that that although the trend of variation always shows an increase in emulsion stability with mixing speed, but quantitative comparison of the two works could not be attained because the emulsion properties, operating conditions, and the range of mixing speeds used for the two works were observed to be significantly different.

This finding is a logical outcome due to the exertion of the shear force by the homogenizer blade which shears off the droplets into further smaller particles, and hence the active polar molecules such as asphaltanes and resin will possess a higher tendency and greater surface to bind with the water molecules, inhibiting the coalescence of the dispersed phase. 


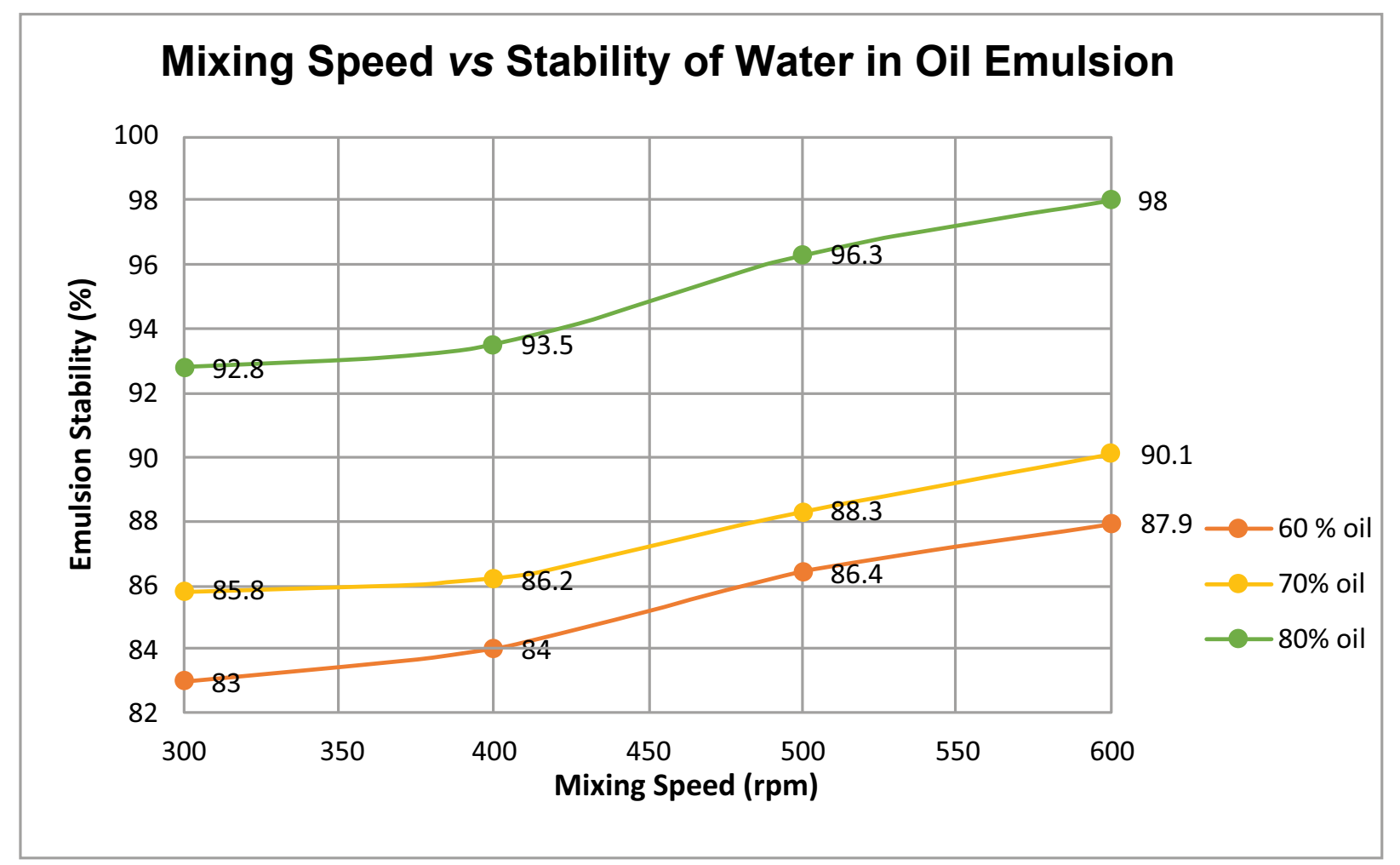

Fig. (7). Relationship of mixing speed on the stability of water in oil emulsion.

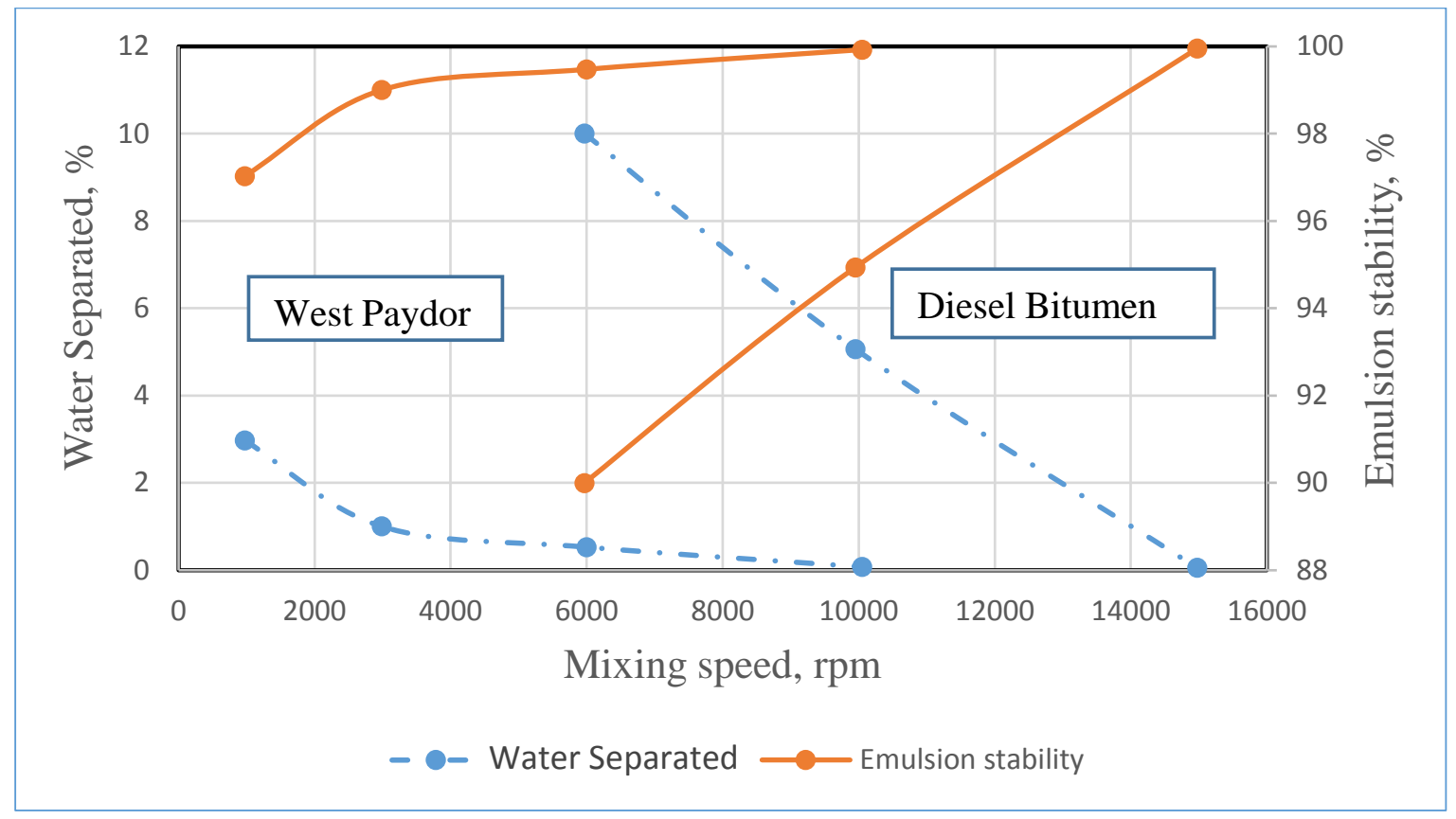

Fig. (8). Effect of mixing speed on the stability of emulsions formulated from two types of oils as suggested by Ashrafizadeh and Kamran [16].

From the plot it can be observed that the crude oil content of $60 \%$ at $300 \mathrm{rpm}$ exhibited a very poor stability as the shearing force did not reduce the droplet size. As the crude oil content was $60 \%$, the synthesized brine content increased up to $40 \%$ and with the increase in brine content, there was a decrease in emulsion stability. $600 \mathrm{rpm}$ was considered as the shearing rate resulting in the maximum emulsion stability. It was, nevertheless, noted that the minimum mixing time of 15 minutes was required to homogenize emulsion. After this minimum mixing time, emulsion started to turn creamy 
and viscous as it turns out to be inseparable in nature even for 5 days. This result indicates that there will be a phase shift if the mixture is mixed at higher speed for long time.

\subsection{Efficiency of Demulsifier Concentration (Bottle Test)}

To investigate the efficiency of the PVP demulsifier, Castila Crude was mixed with synthesized brine water with concentration of $30000 \mathrm{ppm}$ Sodium Chloride as discussed in the methodology section. All the experiments have been carried out at temperature of $60^{\circ} \mathrm{C}$ using $20 \%$ water cut. The demulsifier has been tested separately with 8 different concentrations and the efficiency of the separation of water was compared. Kinetics of water separation was determined from Bottle Test analysis using demulsifier concentrations ranging from 10 to 80 ppm as shown in Fig. (9).

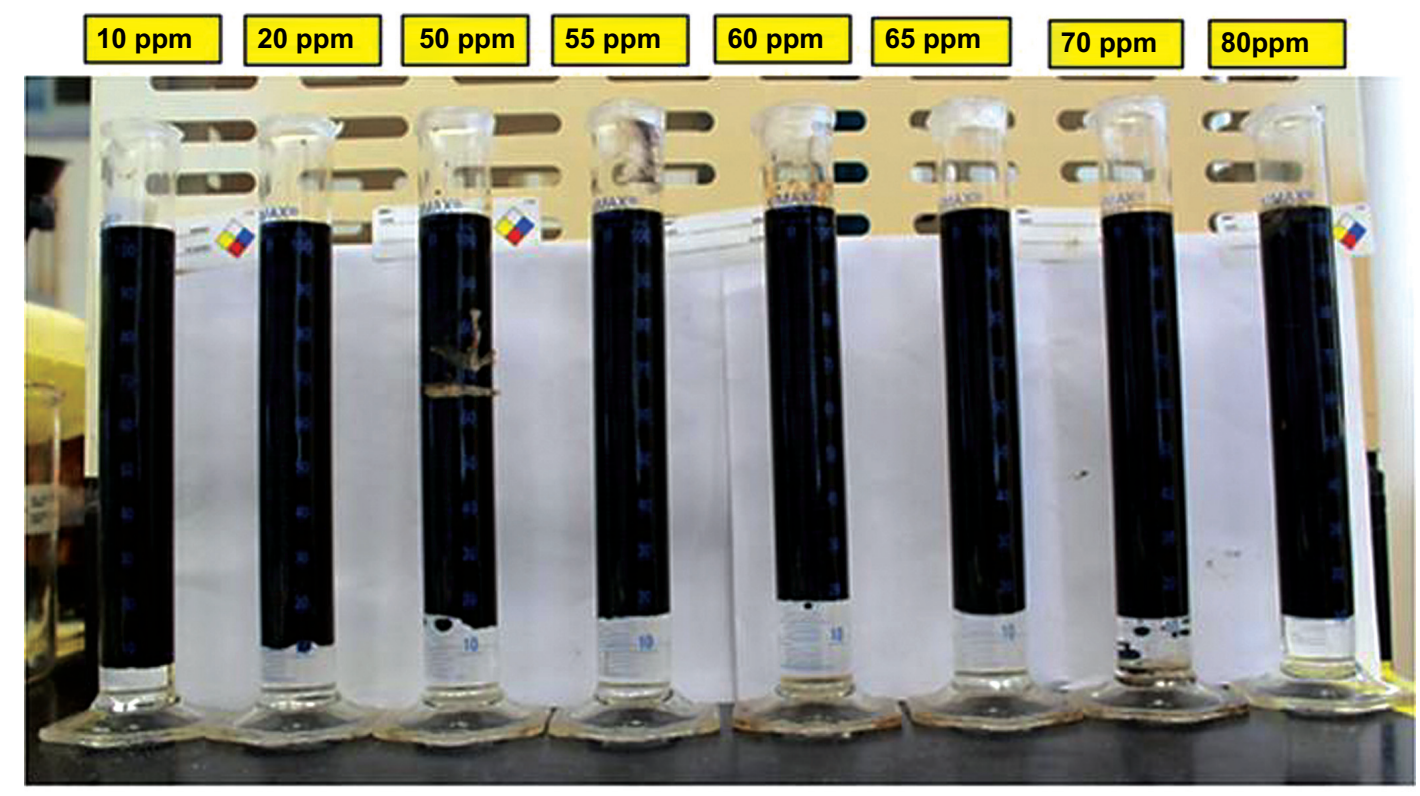

Fig. (9). Bottle Test Analysis.

A large screening was performed with bottle test on the different concentrations of the demulsifier previously mentioned. The purpose of the large screening was mainly to find the optimum concentration for the demulsifier; some part of the result is included in Table 2.

Table 2. Time taken for demulsifier to separate water from emulsion.

\begin{tabular}{|c|c|c|c|c|c|c|c|c|}
\hline \multirow{2}{*}{ TIME(MIN) } & \multicolumn{9}{|c|}{ SEPARATED WATER (\%) } \\
\cline { 2 - 10 } & $\mathbf{1 0} \mathbf{~ p p m}$ & $\mathbf{2 0} \mathbf{~ p p m}$ & $\mathbf{5 0} \mathbf{~ p p m}$ & $\mathbf{5 5} \mathbf{p p m}$ & $\mathbf{6 0} \mathbf{~ p p m}$ & $\mathbf{6 5} \mathbf{p p m}$ & $\mathbf{7 0} \mathbf{~ p p m}$ & $\mathbf{8 0} \mathbf{~ p p m}$ \\
\hline 0 & 0 & 0 & 0 & 0 & 0 & 0 & 0 & 0 \\
\hline 1 & 0 & 0 & 0 & 0 & 0 & 0 & 0 & 0 \\
\hline 2 & 0 & 0 & 40 & 30 & 0 & 5 & 0 & 18 \\
\hline 3 & 0 & 8 & 42 & 32 & 10 & 8 & 15 & 26 \\
\hline 4 & 4 & 10 & 54 & 45 & 14 & 21 & 17 & 35 \\
\hline 5 & 5 & 15 & 57 & 47 & 25 & 24 & 22 & 38 \\
\hline 6 & 6 & 22 & 60 & 50 & 30 & 29 & 32 & 40 \\
\hline 7 & 7 & 30 & 61 & 51 & 40 & 30 & 45 & 43 \\
\hline 8 & 8 & 40 & 63 & 53 & 52 & 34 & 52 & 45 \\
\hline 9 & 9 & 41.5 & 65 & 56 & 58 & 38 & 58 & 46 \\
\hline 10 & 10 & 45 & 68 & 59 & 60 & 40 & 59 & 48 \\
\hline 11 & 10.5 & 49 & 69 & 59 & 68 & 45.2 & 65 & 49 \\
\hline 12 & 10.8 & 50 & 70 & 62 & 72 & 48.5 & 69 & 49.6 \\
\hline 13 & 11 & 51 & 71 & 62 & 75 & 51 & 70 & 52 \\
\hline 14 & 12 & 53 & 73 & 63 & 80 & 56 & 73 & 53 \\
\hline
\end{tabular}


(Table $\square$ ) contd.....

\begin{tabular}{|c|c|c|c|c|c|c|c|c|}
\hline \multirow{2}{*}{ TIME(MIN) } & \multicolumn{8}{|c|}{ SEPARATED WATER $(\%)$} \\
\hline & 10 ppm & 20 ppm & 50 ppm & 55 ppm & $60 \mathrm{ppm}$ & 65 ppm & 70 ppm & 80 ppm \\
\hline 15 & 13 & 55 & 75 & 65 & 91 & 57 & 73 & 54 \\
\hline 16 & 14 & 58 & 75.6 & 66.5 & 92 & 60 & 73 & 56 \\
\hline 17 & 14 & 60 & 75.9 & 67 & 93 & 62 & 73 & 56 \\
\hline 18 & 14 & 61 & 82 & 72 & 93.5 & 63 & 73 & 56 \\
\hline 19 & 15 & 62 & 83 & 75 & 94 & 63 & 73 & 56 \\
\hline 20 & 16 & 62 & 84 & 78 & 94.5 & 68 & 73 & 56 \\
\hline 21 & 16.5 & 62 & 86 & 80 & 95 & 70 & 73 & 56 \\
\hline 22 & 17 & 62 & 86 & 81.5 & 95.5 & 72 & 73 & 56 \\
\hline 23 & 18 & 62 & 86 & 83 & 96 & 72.5 & 73 & 56 \\
\hline 24 & 19 & 62 & 86 & 86 & 100 & 74 & 73 & 56 \\
\hline 25 & 20 & 62 & 86 & 87 & 100 & 75.2 & 73 & 56 \\
\hline 26 & 22 & 62 & 86 & 88 & 100 & 76.9 & 73 & 56 \\
\hline 27 & 25 & 62 & 86 & 90 & 100 & 78 & 73 & 56 \\
\hline 28 & 27 & 62 & 86 & 90 & 100 & 82 & 73 & 56 \\
\hline 29 & 29 & 62 & 86 & 91 & 100 & 83.6 & 73 & 56 \\
\hline 30 & 30 & 62 & 86 & 91.5 & 100 & 84.2 & 73 & 56 \\
\hline
\end{tabular}

The complete results obtained from the optimum concentration for the demulsifier are illustrated graphically as shown in Fig. (10). The curve indicates that the optimum dose of the demulsifier was $60 \mathrm{ppm}$ which enabled the separation of more than $80 \%$ of the water after 15 minutes of application and enabled total separation of the two phases after 25 minutes. The curve also indicates that all other doses couldn't provide total separation of the two phases regardless of the time. For example, $10 \mathrm{ppm}$ could only separate less than $40 \%$ of the water after 45 minutes and then no more water is separated.

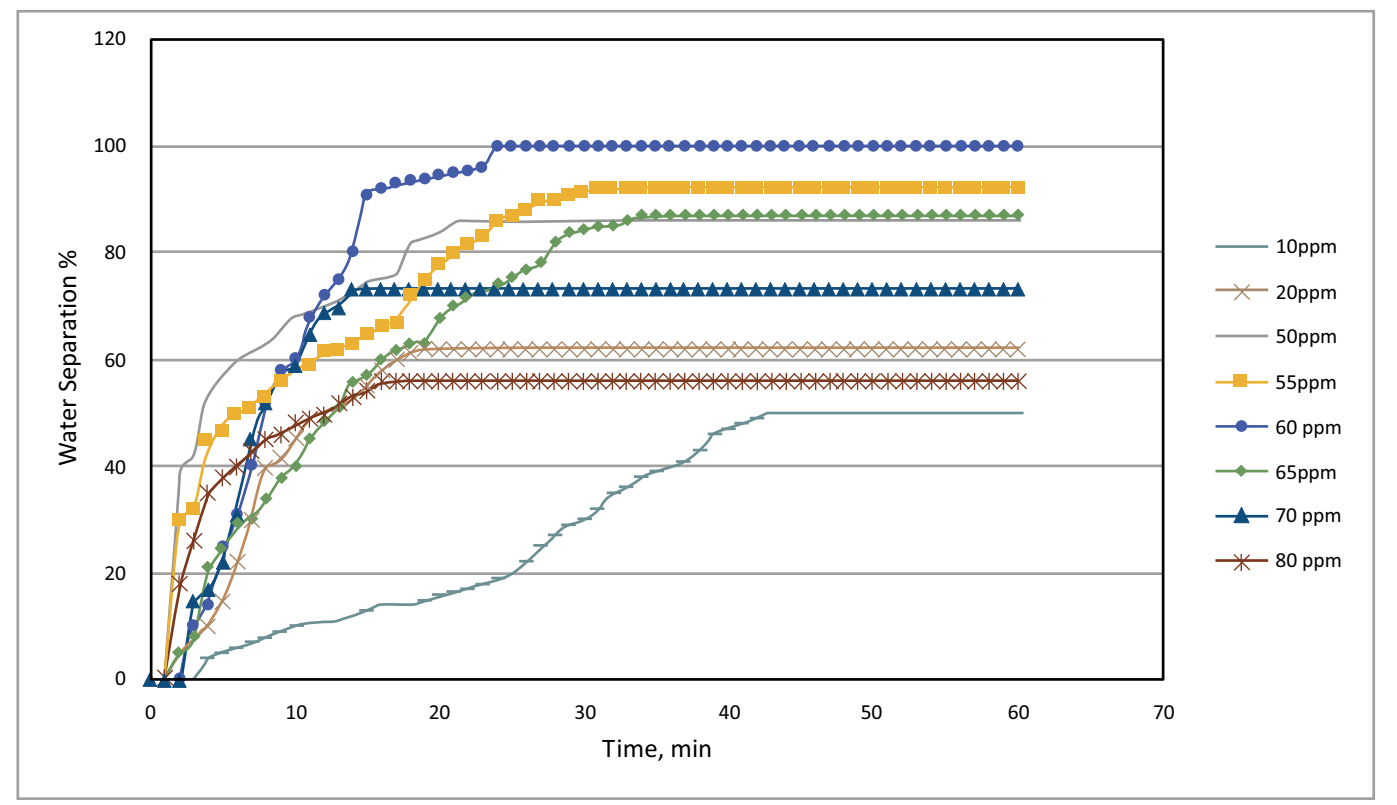

Fig. (10). Water separation time at different demulsifier concentrations.

Fig. (11) depicts the performance of the demulsifier at different concentrations. Comparing the water separated at concentration ranging from $60 \mathrm{ppm}$ to $80 \mathrm{ppm}$, it can be observed that water separation decreased from $87 \%$ at $65 \mathrm{ppm}$ to $74 \%$ at $70 \mathrm{ppm}$ and became $53 \%$ at $80 \mathrm{ppm}$ with all values less than the water separated at $60 \mathrm{ppm}$. This is because excessive demulsifier addition can negatively affect the efficiency of emulsion breakdown. As stated by Becher [9], excessive formation of demulsifier at the droplet surface can create a highly viscoelastic film which will cause more stabilization of the dispersed phase and isolation of the demulsifying molecules. Becher also pointed out that this affect can be observed at higher shear viscosity and higher demulsifier concentration. 


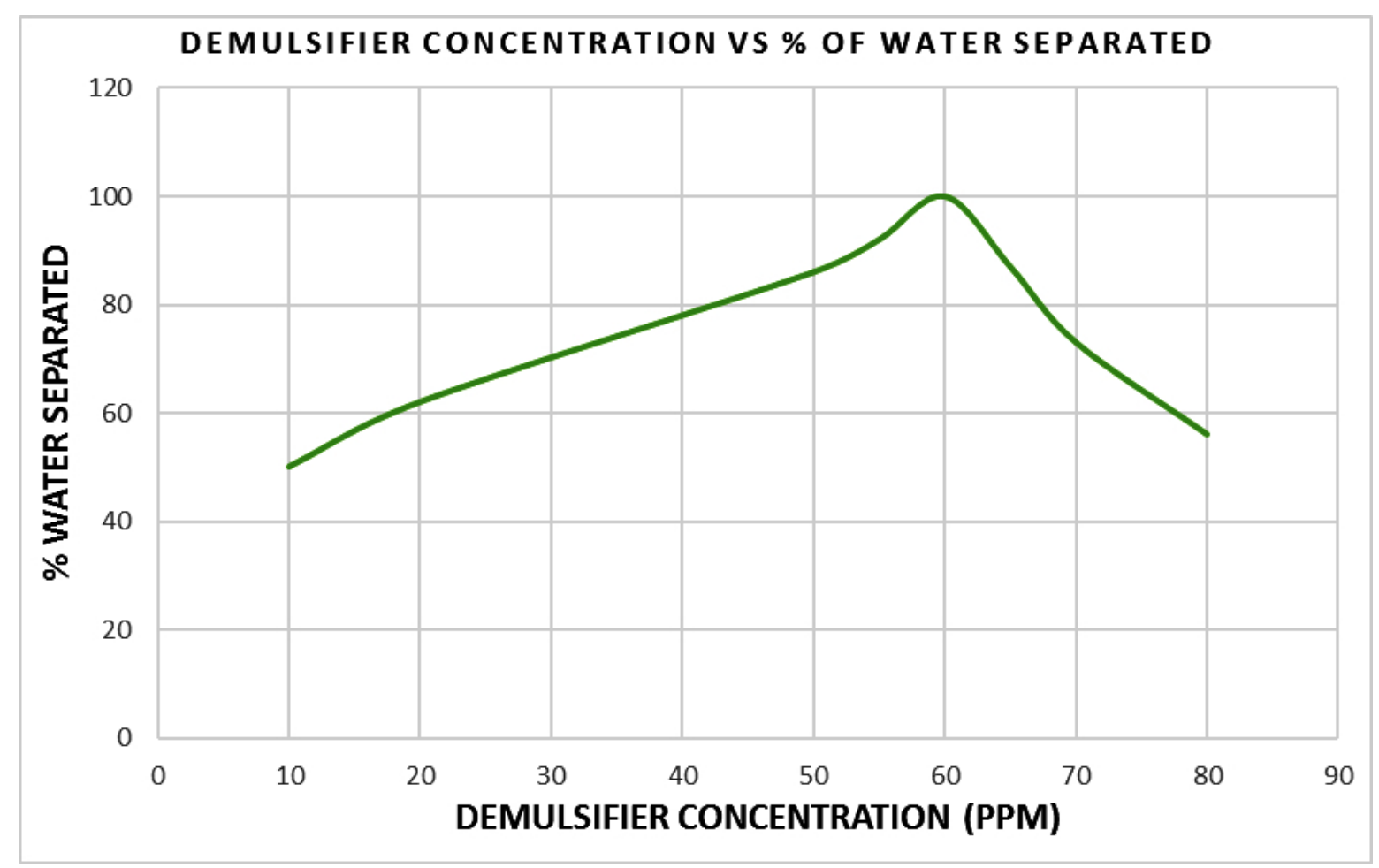

Fig. (11). Relationship between demulsifier concentration and percentage of water separated.

The details of chemical demulsifier's behaviour at oil water interface and their role in destabilizing emulsion can be determined from their effect on interfacial films via film-balanced experiment. Jones, Neustadter, \& Whittingham [11], stated that the separation of water from water in oil emulsion can be sensitive to the concentration of demulsifier. The results indicate that $10 \mathrm{ppm}$ of demulsifier was able to separate $50 \%$ of the water from the emulsion. But it took 40 minutes to reach the maximum level of separation. At demulsified concentration of $60 \mathrm{ppm}$, no further water separation was observed after 24 minutes in the entire sample tested. It was found that $60 \mathrm{ppm}$ allowed a very fast separation of the water and reached at peak after 23 minutes. Concentration of $60 \mathrm{ppm}$ is, therefore, considered as the optimum demulsifier concentration.

\subsection{Comparison with Previous Work}

There are limited works in the literature concerning the application of Polyvinylpyrrolidone (PVP) as demulsifier. Again, because of the inconsistency of the testing conditions and fluid properties, it is difficult to obtain a quantitative comparison between the current work and the previous works. Therefore, the objective of this section is just to show a comparison based on trends variation rather comparison between the values. The earliest evidence of the application that we came across in the literature is the work conducted by H. Mat and his co-workers [13] who investigated PVP in combination with other 12 oil-soluble demulsifiers. Fig. (12) shows how the volume of separated oil changed with time due to the effect of PVP as extracted from their experimental results. Comparing this trend with our result in Fig. (10), it can be easily noticed that the two results fairly agree in the trend of variation, which indicate an acceptable validation of the current work (considering that the PVP concentration and time duration used in the two works are different). It is worthless to mention that in our result, Y-axis represents the separated water whereas in Fig. (12), it represents the separated oil.

Another finding of exhibition of PVP as demulsifier was reported by Razi and others as a result of experimental investigation of many oil soluble chemicals including PVP [14]. They presented a curve showing the relationship between water separation and time for different demulsifiers including PVP. With PVP, only $10 \%$ of water was separated after 10 hours which remained constant until 25 hours from the beginning of the test. They also pointed out that PVP resulted in insignificant reduction in interfacial tension. 


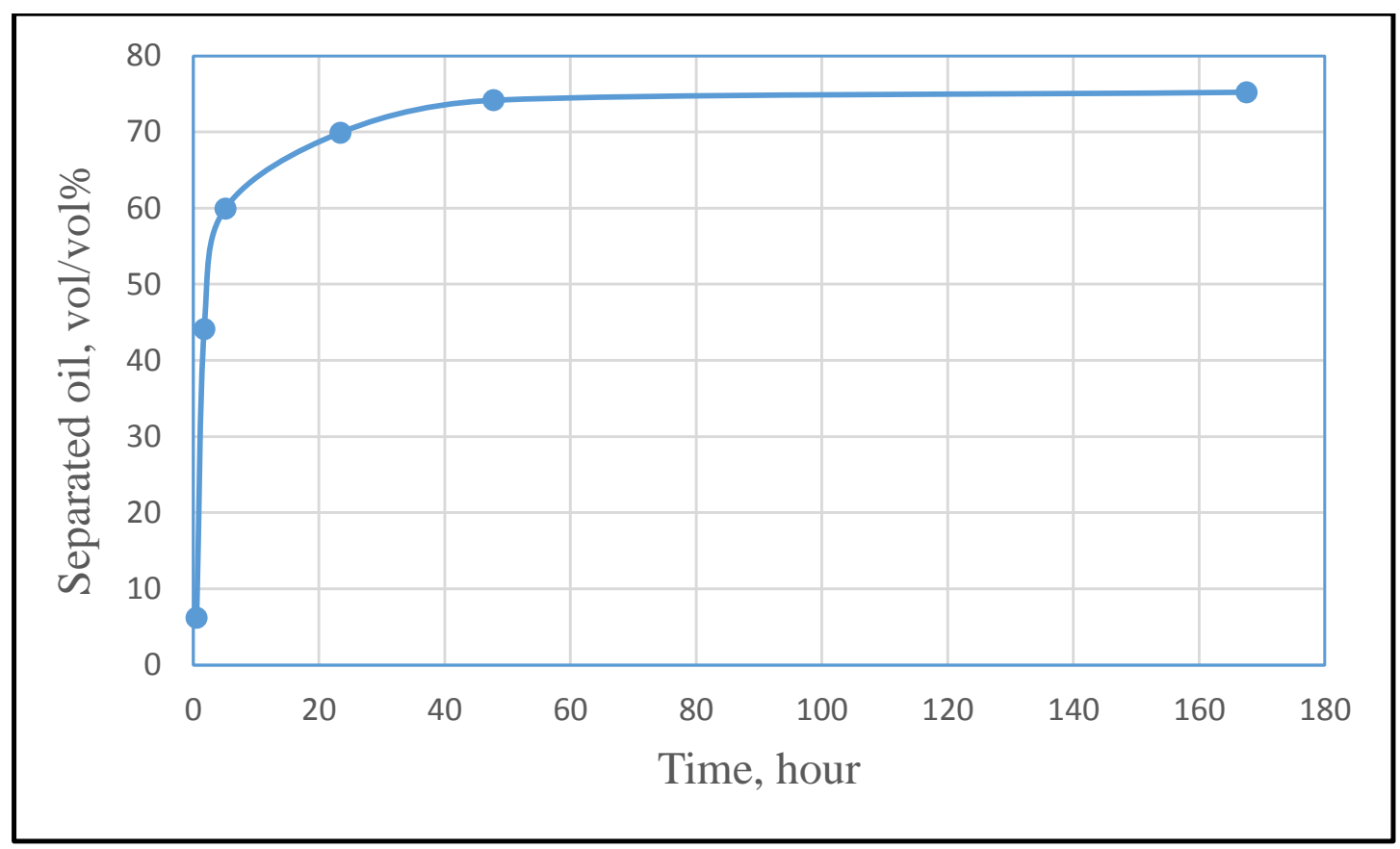

Fig. (12). Oil separation during 168 hours by using oil-soluble demulsifiers. Experimental conditions: $\mathrm{T}$, $70^{\circ} \mathrm{C}$; Demulsifier concentration, $10 \mathrm{ppm}$, reproduced from $\mathrm{H}$. Mat and his co-workers [13].

To conclude the comparison with the previous work, for different types of oil and different test conditions, PVP may perform with different degrees of demulsification efficiency. But the general trend is acceleration of emulsion separation with time until a specific time duration, after which the amount of separation becomes constant.

\section{CONCLUSION}

The demulsification performance of Polyvinylpyrrolidone (PVP) on water-in-oil emulsion has been examined experimentally using bottle test experiments. The experiments were conducted at temperature of $60^{\circ} \mathrm{C}$ on emulsion samples formed by mixing a crude oil with $20 \%$ synthesized brine water. Before investigating the effect of PVP, the stability of the formed emulsion was confirmed by using Turbiscan MA 2000. The following points can be pointed out as conclusion of this work:

1- The blain emulsion formulated from Castila crude oil mixed with brine is very stable at ambient conditions and its stability increases with the increase of shearing (mixing speed).

2- The addition of PVP to the blain emulsion results in imposing significant demulsification effect which will accelerate the emulsion separation (decrease the stability.

3- The performance of PVP can be improved by increasing its concentration. However, there is an optimum concentration value, above which, excessive addition will result in reverse effect.

4- The optimum dose of the PVP demulsifier is $60 \mathrm{ppm}$ which enables the separation of more than $80 \%$ of the water after 15 minutes of application and enables total separation of the two phases after 25 minutes.

5- All the investigated doses other than $60 \mathrm{ppm}$ couldn't provide total separation of the two phases regardless of the time.

\section{CONSENT FOR PUBLICATION}

Not applicable.

\section{CONFLICT OF INTEREST}

The authors declare no conflict of interest, financial or otherwise. 


\title{
ACKNOWLEDGEMENTS
}

\author{
Declared none.
}

\section{REFERENCES}

[1] W. Wang, J. Gong, and P. Angeli, "Investigation on heavy crude-water two phase flow and related flow characteristics", Int. J. Multiph. Flow, pp. 1156-1164, 2011 [http://dx.doi.org/10.1016/j.ijmultiphaseflow.2011.05.011]

[2] J. Sjöblom, L. Mingyuan, and A. A. Christy, "Water-in-crude-oil emulsions from the Norwegian continental shelf 7. Interfacial pressure and emulsion stability", Colloids Surf., vol. 66, no. 1, 1992. [http://dx.doi.org/10.1016/0166-6622(92)80120-Q]

[3] L.F. Richard, "Agents which promote and stabilize water-in-oil emulsions", Spill Sci. Technol. Bull., vol. 5, no. 2, pp. 117-126, 1999. [http://dx.doi.org/10.1016/S1353-2561(98)00028-0]

[4] C.D. Noik, "Mechanism of crude oil and water interface destabilization by silicon demulsifiers", Soc. Petrol. Eng., 2013.

[5] M. Emuchay, N.A. Onyekonwu, C. Ogolo, and C. Ubani, "Breaking of emulsion using locally formulated demulsifiers", In: SPE Nigeria Annual International Conference and Exhibition, Logos, 2013. [http://dx.doi.org/10.2118/167528-MS]

[6] J. Minne, "Treatment of crude oil emulsions", $I^{\text {st }}$ World Petroleum Congress, 1933

[7] L. Oyekunle, "Certain relationships between chemical composition and properties of petroleum asphalts from different origin", Oil Gas Sci. Technol., vol. 61, no. 61, pp. 433-441, 2006. [http://dx.doi.org/10.2516/ogst:2006043a]

[8] Auflem, "Influence of asphaltene aggregation and pressure on crude", PhD thesis, Norwegian University of Science and Technology, 2002.

[9] J.R. Becker, Crude Oil Waxes, Emulsions, and Asphaltenes.y, 4 ed., Pennwell Publishing Company, 1997.

[10] D.P. Ortiz, E. Baydaka, and H.W. Yarranton, "Effect of surfactants on interfacial films and stability of water-in-oil emulsions stabilized by asphaltenes", J. Colloid Interface Sci., vol. 35, no. 2, pp. 542-555, 2010.

[11] T. Jones, E.L. Neustadter, and K.P. Whittingham, "Water in crude oil emulsion stability and emulsion destabilization by chemical demulsifiers", J. Can. Pet. Technol., vol. 17, no. 2, 1978.

[12] M. Fingas, B. Fieldhouse, and J. Mullin, "Water-in-oil emulsions: How they are formed and broken", Oil Spill Conference, 1995 [http://dx.doi.org/10.7901/2169-3358-1995-1-829]

[13] H. Mat, and A. Samsuri, W. A. RAHMAN and S. I. Rani., Study on demulsifier formation for treating Malysian crude oil emulsion: Universiti Teknologi Malaysia, Malaysia, 2006.

[14] M. Razi, M.R. Rahimpour, A. Jahanmiri, and F. Azad, "Effect of a different formulation of demulsifiers on the efficiency of chemical demulsification of heavy crude oil", J. Chem. Eng. Data, pp. 2936-2945, 2011. [http://dx.doi.org/10.1021/je2001733]

[15] M.S. Cerimedo, C.H. Iriart, R.J. Candal, and M.L. Herrera, "Stability of emulsions formulated with high concentrations of sodium caseinate and trehalose", Food Res. Int., vol. 43, pp. 1482-1493, 2010. [http://dx.doi.org/10.1016/j.foodres.2010.04.008]

[16] S.N. Ashrafizadeh, and M. Kamran, "Emulsification of heavy crude oil in water for pipeline transportation", J. Petrol. Sci. Eng., vol. 71, no. 3, pp. 205-211, 2010.

[http://dx.doi.org/10.1016/j.petrol.2010.02.005]

(C) 2017 Mohyaldinn et al.

This is an open access article distributed under the terms of the Creative Commons Attribution 4.0 International Public License (CC-BY 4.0), a copy of which is available at: https://creativecommons.org/licenses/by/4.0/legalcode. This license permits unrestricted use, distribution, and reproduction in any medium, provided the original author and source are credited. 